\title{
Phonological and orthographic visual word recognition in the two cerebral hemispheres: Evidence from Hebrew
}

\author{
Eva Smolka \\ Department of Psychology, Philipps-University Marburg, Germany \\ Zohar Eviatar \\ Department of Psychology, University of Haifa, Haifa, Israel
}

\begin{abstract}
Studies on the cerebral mechanisms of reading have mostly used Latin-based writing systems and assume that the left, but not the right, cerebral hemisphere is capable of phonological processing. The present study used Hebrew as the test language to examine the effects of phonological and orthographic information in the two hemispheres. In unvoweled Hebrew script, words are read via consonant information alone. We used two naming tasks with an interference paradigm, where phonemically, orthographically, and figurally incorrect vowel information conflicted with the consonant information of words presented in the left, right, or central visual fields. Interference patterns indicated that the left hemisphere automatically transforms graphemes into phonemes (Experiments 1 and 2), whereas the right hemisphere processes vowel diacritics as visual objects (Experiment 1), although it possesses some phonological categories (Experiment 2). The significance of these findings for models of visual word recognition in the cerebral hemispheres is discussed.
\end{abstract}

The research reported below explored how the cerebral hemispheres recognize visually presented words. Specifically, we examined how hemispheric abilities interact with phonological and orthographic information in Hebrew words. In Hebrew, the graphemic representation of the phonological forms of words can be manipulated, which facilitates the conceptual distinction of phonological versus orthographic processes in word recognition.

In general, models of visual word recognition posit separate phonological and orthographic mechanisms that relate a visually presented word to the semantic system (e.g., Coltheart, Rastle, Perry, Langdon, \& Ziegler, 2001; Frost, 1998; Harm \& Seidenberg, 2001; Plaut, 1997; Van Orden, Jansen op de Haar, \& Bosman, 1997). However, these models differ in the relative importance that they attribute to these processing mechanisms and in their general assumptions about the default procedure during reading. For example, strong phonological theories and recent connectionist network models (Frost, 1998; Harm \& Seidenberg, 2001; Lukatela, Lukatela,

Correspondence should be addressed to Eva Smolka, Experimental and Biological Psychology, Philipps-University Marburg, Gutenbergstrasse 18, 35032 Marburg, Germany (E-mail: smolka@staff.uni-marburg.de) or to Zohar Eviatar, Department of Psychology, University of Haifa, 31908 Haifa, Israel (E-mail: zohare@psy.haifa.ac.il).

We would like to thank Ruth Kimchi, David Plaut, and an anonymous reviewer for many helpful comments. The first experiment was presented at the XIth Conference of the European Society for Cognitive Psychology. 
Carello, \& Turvey, 1999; Van Orden, Pennington, \& Stone, 1990) assume that the phonological processing of a printed word is the default procedure of the cognitive system. In contrast, versions of the dual-route model hold that visual-orthographic processing develops with reading practice to surpass phonological processing, so that either both routes operate in parallel (Paap, Noel, \& Johansen, 1992) or high-frequency words are processed faster along the visualorthographic route (e.g., Coltheart, Curtis, Atkins, \& Haller, 1993; Jackson \& Coltheart, 2001; Taouk \& Coltheart, 2004).

For over a century, the consensus has been that the left hemisphere (LH) is crucial for language processes, but recent research presents evidence for a right-hemisphere $(\mathrm{RH})$ role in language processing, primarily in the comprehension of word meanings (e.g., Beeman, 1998; Chiarello, 1998; Zaidel, 1987). Converging evidence from commissurotomy patients (e.g., Baynes \& Eliassen, 1998; Zaidel, 1998; Zaidel, Zaidel, \& Bogen, 1990), focal lesion studies (e.g., Copland, Chenery, \& Murdoch, 2002; Tompkins \& Lehman, 1998), developmental and acquired dyslexia (e.g., Castles \& Coltheart, 1993, 1996; Coltheart, 2000; Coslett \& Saffran, 1998; Hanley \& McDonnell, 1997; Saffran \& Marin, 1977; Schweiger, Zaidel, Field, \& Dobkin, 1989), as well as from neurologically intact subjects (e.g., Chiarello, 1985, 1988; Coney, 2002; Ellis, Young, \& Anderson, 1988; Eviatar \& Zaidel, 1991, 1992; Jordan, Patching, \& Thomas, 2003; Lavidor \& Ellis, 2003; Pugh et al., 1997; Rayman \& Zaidel, 1991) indicates that both hemispheres participate in word processing, though in qualitatively different ways.

One important source for hemispheric differences in phonological and visual-orthographic processing stems from commissurotomy patient L.B. (Zaidel \& Peters, 1981). Phonological tasks were perfectly mastered by L.B.'s disconnected $\mathrm{LH}$, while his disconnected $\mathrm{RH}$ demonstrated a pattern of restricted phonological abilities, suggesting that it could address the phonology of words (L.B.'s RH could comprehend single spoken words, match a spoken word with the picture of its referent, and match the picture of an object with the picture of another object with a rhyming name). However, it could not assemble phonology from orthography (L.B.'s disconnected $\mathrm{RH}$ could neither match a printed word with a picture of an object with a rhyming name nor match written rhymes).

Thus, in terms of Seidenberg and McClelland's (1989) triangle model, it seems as if L.B.'s RH maintained the components that connect phonology and semantics as well as orthography and semantics, but not the direct connection between orthography and phonology.

Although the findings of L.B.'s reading abilities must not be generalized for normal reading, they are informative about the reading abilities of the isolated right hemisphere (Zaidel, 1998 ${ }^{1}$ ) and hint at two different networks in the cerebral hemispheres involved in reading: In the LH network, the representations of orthographic, phonological, and semantic information are fully interconnected, and the phonological form of a printed word is directly computed from its orthographic form, whereas in the $\mathrm{RH}$ network, phonological forms are accessed indirectly, via semantics (Peleg, Eviatar, Manevitz, \& Hazan, 2005).

The majority of the neuropsychological data cited above were observed in English-speaking participants performing reading tasks in English. Given that languages differ greatly in the orthographic representation of their sounds, and that orthographic depth has been suggested to result in dissimilar weights given to the phonological and orthographic routes (Frost \& Bentin, 1992), cross-language research is necessary to test the generalizability of neuropsychological conclusions drawn from only one language (Eviatar, 1999, 2000).

\footnotetext{
${ }^{1}$ Zaidel (1998) pointed out that "language in the disconnected right hemisphere following complete cerebral commissurotomy permits assessment of positive language competence, presumably free of callosally mediated inhibitory effects of left aphasiogenic lesions."
} 
Due to the structure of Latin-based writing systems, all of the previous lateralization studies that focused on grapheme-phoneme relations used the detection of poetic rhyme or alliteration as an indication for phonological processing. However, poetic rhyme and alliteration are more complex processes than simple grapheme-tophoneme conversion. More specifically, the judgement of two rhyming words involves the comparison of the phonological rhyme (nucleus and coda) of the respective words. Only if nuclei and codas of syllables are found to be identical can a positive judgement of rhyme be given (Wiese, 1996, p. 45). Moreover, it is under discussion whether reading skills for Latin-based orthographies depend on letter, grapheme, or onset-rhyme coding (e.g., Goswami, 2002; Goswami, Ziegler, Dalton, \& Schneider, 2003; Rey, Ziegler, \& Jacobs, 2000). Hence, in order to study simple grapheme-to-phoneme conversion, a test other than rhyme judgement or rhyme perception must be applied. By using Hebrew, the present study is able to examine whether single graphemes are converted into the corresponding phonemes.

The Hebrew writing system is characterized by a special denotation of vowel information, which provides the opportunity to manipulate the amount of explicit phonological information within a word: The 22 letters of the alphabet represent mostly consonants, while a "pointing" system of diacritics attaches the vowels to the consonants. These diacritics, such as .. and (representing vowels $/ \varepsilon /$ and $/ \mathrm{a} /$, respectively), are attached mostly below, but also above or in between the consonant letters, so that they are visually easy to distinguish from consonants. In addition, four of the consonant letters (

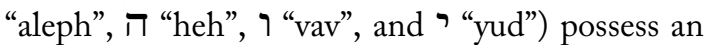
alternative reading as vowels, and the five main vowels $(/ \mathrm{i} /, / \mathrm{v} /, / \varepsilon /, / \mathrm{\jmath} /$, and $/ \mathrm{a} /)$, are represented redundantly by these dual-function letters and diacritics (Berman, 1997). Vowel diacritics fully specify the phonological form of an orthographic string and make it completely transparent in terms of grapheme-phoneme relations, disambiguating its lexical meaning. Hebrew, in its pointed form, is thus a completely shallow orthography, whereas the unpointed script is a deep orthography, with a limited amount of vowel information and a large number of homographs (Katz \& Frost, 1992; Shimron, 1993). Nonetheless, diacritics are omitted in everyday use and are only inserted in a context-dependent manner. Hence, the skilled adult reader is exposed mostly to a script where the phonological form of a single printed word remains ambiguous and requires semantic and syntactic processes in text comprehension to resolve this ambiguity.

The insertion or omission of vowel diacritics in pointed or unpointed Hebrew can be applied as a manipulation of phonological ambiguity to study phonological processing. Since pointing represents vowels, and vowels represent phonological information, pointing is assumed to convey phonological information in the visual word recognition process.

Research on the effects of pointing in Hebrew showed that the naming of unambiguous words was facilitated when these were presented in pointed script (Frost, 1994, 1995; Koriat, 1984), while lexical decisions did not benefit from pointing (Bentin \& Frost, 1987; Frost, 1994, 1995; Koriat, 1984, 1985a; for an exception, see Koriat, 1985b). Only studies that applied an interference paradigm demonstrated automatic processing of vowel information for naming as well as for verbal lexical decisions and semantic judgements (Navon \& Shimron, 1981, 1985; Shimron \& Navon, 1982). These authors used an interference paradigm in which vowel information conflicted with the response suggested by the relevant consonant information. Native Hebrew speakers were presented with correctly pointed words, unpointed words, and "phonemically distorted" pointing, in which the vowels turned the sound of a word into a nonword. Although participants were instructed to ignore the vowel information, responses for phonemically incorrect pointing were considerably decelerated, indicating that participants were not able to disregard the presented vowel information. In addition, "graphemically distorted" pointing was applied, in which orthographically incorrect diacritics changed the visual pattern of a word, but 
nevertheless preserved its correct sound. This kind of pointing was introduced to control for the fact that phonemically incorrect pointing also provided incompatible visual cues. The fact that orthographically incorrect pointing did not interfere with naming latencies suggested that the interference produced by phonemic distortion was due to phonological processing. The authors concluded that vowel graphemes are automatically translated into phonemes.

Assuming that interference paradigms are the optimal way to test automatic processes (Besner \& Stolz, 1998), we adapted the paradigm used by Navon and Shimron (1981, 1985) for use with lateralized presentations. To compare the unilateral visual fields, we used a divided visual-field paradigm, where stimuli are presented outside the centre of gaze in either the left or the right visual hemifield (LVF, RVF). Although information presented in the peripheral visual fields is rapidly transferred to both hemispheres, this paradigm is thought to emphasize the processing characteristics of the hemisphere contralateral to the visual field being stimulated (e.g., Hellige, 1993; Iacoboni \& Zaidel, 1996; Zaidel, 1983; for electrophysiological support for this assumption, see Coulson, Federmeier, Van Petten, \& Kutas, 2005).

Performance on language tasks in which stimuli are presented in the periphery may be qualitatively different from performance of such tasks in central presentations, where presumably both hemispheres perceive the stimulus (Scott $\&$ Hellige, 1998). We therefore included a central presentation condition (CVF) as partial replication of previous, nonlateralized psycholinguistic studies on pointing interference (Navon \& Shimron, 1981, 1985; Shimron \& Navon, 1982).

\section{EXPERIMENT 1}

In Experiment 1, participants were asked to ignore vowel information and to name words presented in three pointing conditions: correct pointing, phonemically incorrect pointing, and figural pointing (see Table 1). Phonemically incorrect pointing was assumed to represent phonological noise. However, the unfamiliar appearance of phonemically incorrect pointing also induces visual noise. In order to control for this type of visual noise, a figural pointing condition was introduced as a nonlinguistic control, using triangles, cubes, and squares in the place of diacritics.

It is important to point out that the manipulation of diacritics does not contrast lexical and sublexical processes in the reading of Hebrew. In Hebrew, both unpointed and correctly pointed words are valid stimuli for direct lexical access (in terms of the dual-route model). Even an incorrectly pointed word can still be a valid stimulus for direct lexical access, if the incorrect diacritics are ignored, and the naming of the word is achieved via its consonant structure alone. In contrast, incorrect vowel graphemes cannot be read via lexical processing, and interference effects caused by any type of incorrect pointing reflect processing of the sublexical path. Thus, in our study we do not contrast lexical versus sublexical processing but rather compare the relative weights of visual

Table 1. Pointing conditions in Experiments 1 and 2

\begin{tabular}{|c|c|c|c|}
\hline Type of pointing & Example & Pointing-induced pronunciation & Type of noise \\
\hline Correct & שְִִׁג & [sheleg] & - \\
\hline Phonemic & שָָלָג & [shalag] & phonological and visual \\
\hline Figural & של & [sheleg] & visual (language irrelevant) \\
\hline Orthographic & שִׁלְג & [sheleg] & visual (language relevant) \\
\hline
\end{tabular}

Note: Correct, phonemic, and figural pointing conditions were applied in Experiment 1; orthographic pointing was added in Experiment 2 . 
versus phonological features of diacritics during visual word recognition.

If phonemically incorrect pointing interferes with word recognition in the $\mathrm{RH}$, this should result from the addition of visual noise to the stimulus and should resemble the interference of figural pointing. In contrast, if the $\mathrm{LH}$ processes diacritics as phonological attributes of a word, phonological noise should be harder to ignore than visual noise. Phonemically incorrect pointing should thus interfere with word recognition in the $\mathrm{LH}$ to a greater extent than does figural pointing.

\section{Method}

\section{Participants}

A total of 40 Haifa university students participated in the experiment for course credit. A questionnaire assessed that they were right-handed native speakers of Hebrew who were not dyslexic, had not suffered from brain injuries, and had normal or corrected-to-normal vision.

\section{Materials}

The stimuli consisted of 216 Hebrew nouns. The consonant pattern of each word was unambiguous, since it allowed only one pronunciation and meaning in unpointed script. Words were three to four letters long and contained two or three vowels. Words did not include the dual-function letters ' ("yud") and ר ("vav") that may represent the vowels $/ \mathrm{i} / \mathrm{\rho} / \mathrm{\jmath} /$ and $/ \mathrm{v} /$. Thus, only words with vowels $/ \mathrm{a} /$ or $/ \varepsilon /$ were used, represented by diacritics below the consonant letters. Vowel /a/ was represented by the diacritics ("kamats") and _. ("patah"), and vowel / $/ \varepsilon /$ by ${ }^{\text {. } . . ~(" s e g o l ") ~}$ and .. ("tsere"). The average frequency of each word included in the word list was above 3 as judged on a 7 -point scale from very infrequent (1) to very frequent (7). ${ }^{2}$

Each word-represented by its consonantswas presented in three pointing versions, as shown in Table 1: (a) Correct pointing (CP) supplied the correct diacritics; (b) phonemic pointing
(PP) provided diacritics that phonemically distort the word and produce a nonword; for this purpose, diacritics designating the vowel /a/ and those designating / $\varepsilon /$ were interchanged-specifically, "kamats" was exchanged with "segol", and "patah" with "tsere"; (c) figural pointing (FP) supplied figurative nonsense signs that neither orthographically nor phonologically represent vowels. Specifically, correct diacritics were replaced by little triangles, cubes, and circles in the size of the pointing patterns.

\section{Apparatus}

Stimuli were presented on a Silicon Graphics workstation model Personal Iris 4D30. Naming latencies were monitored by a microphone connected to a voice key, and response accuracy was recorded by the experimenter.

\section{Procedure}

Each of the 216 words appeared in all pointing (CP, PP, FP) by visual field (CVF, LVF, RVF) conditions. Because every participant should see a word only once, the different pointing by visual field conditions of the same word were allocated to nine lists by a Latin square design. Each list was further subdivided into three blocks of 72 items each. The order of items and visual field conditions within a list were randomized; shuffling was repeated until maximally four words or nonwords were presented consecutively. Participants were randomly assigned to a list.

Participants were tested individually in a dimly lit room and were seated at a viewing distance of $57 \mathrm{~cm}$ from the screen with their heads rested on a chin rest. Prior to the experiment, nine items were used to familiarize participants with the different pointing and visual field conditions, after which participants ran through 45 practice trials.

Each trial started with a $1,000-\mathrm{Hz}$ sound for $100 \mathrm{~ms}$, followed by a fixation cross in the centre of the screen for $1,000 \mathrm{~ms}$, after which the target word appeared for $160 \mathrm{~ms}$, immediately followed by a blank screen. The intertrial interval was

\footnotetext{
${ }^{2}$ We thank Ram Frost for kindly providing us with the frequency counts.
}

\section{6}


Table 2. Response latencies and accuracies in Experiment 1

\begin{tabular}{|c|c|c|c|c|c|c|c|c|c|}
\hline \multirow[b]{2}{*}{$\begin{array}{l}\text { Type of } \\
\text { pointing }\end{array}$} & \multicolumn{3}{|c|}{$L V F$} & \multicolumn{3}{|c|}{$C V F$} & \multicolumn{3}{|c|}{$R V F$} \\
\hline & $R T$ & Interference & Error & $R T$ & Interference & Error & $R T$ & Interference & Error \\
\hline Correct & $443(65)$ & & 10.0 & $360(51)$ & & 1.0 & $429(72)$ & & 5.0 \\
\hline Phonemic & $467(71)$ & $25^{* *}$ & 12.8 & $379(51)$ & $20^{* *}$ & 1.4 & $460(87)$ & $32^{* *}$ & 9.4 \\
\hline Figural & $471(67)$ & $29^{* *}$ & 15.3 & $374(48)$ & $14^{* *}$ & 1.2 & $438(65)$ & $10^{*}$ & 9.2 \\
\hline
\end{tabular}

Note: Median RTs in ms (SD in parentheses) and error means of naming responses for correctly, phonemically, and figurally pointed words presented in the left $(\mathrm{LVF})$, central $(\mathrm{CVF})$, or right $(\mathrm{RVF})$ visual fields. Interference effects are calculated relative to the correct pointing condition parentheses.

${ }^{*} p<.05$ indicates significance level in the items analysis; ${ }^{* *} p<.05$ indicates significance levels in both participants and items analyses.

$3,000 \mathrm{~ms}$. In the central visual field condition, the central letter of the stimulus item was presented at the fixation cross; in the left or right visual field conditions, the letter closest to the fixation cross was presented $2 \mathrm{~cm}$ to the left or the right of the fixation cross, subtending a visual angle of approximately $2.5^{\circ}$. Letter size was $0.6 \times 0.6 \mathrm{~cm}$.

Participants were instructed to gaze directly at the fixation cross that appeared before the onset of the target word. They were instructed to ignore the pointing and to name the words as fast as possible. Given the very brief target duration, participants were asked to guess if they were not certain of a word.

\section{Results}

All analyses were performed with participants $\left(F_{1}\right)$ and with items $\left(F_{2}\right)$ treated as the random variable. Reaction times (RTs) were measured from stimulus offset (of $160 \mathrm{~ms}$ ). RTs lower than $100 \mathrm{~ms}$ and higher than 2,500 ms were discarded. Since we were only interested in response latencies and had stressed fast reactions in the instructions, this resulted in high error rates in some cells. The data of participants with error rates higher than $33.3 \%$ in a condition were removed, so that 32 participants remained in the data analyses (mean error rate was $7.3 \%$ ). ${ }^{3}$ Median RTs and error means over participants were positively correlated, $r(286)=.44, p<.0001$, indicating that there was no speed-accuracy trade-off. Response latencies and accuracies are summarized in Table 2.

\section{Visual field differences}

The main interest of the study was to explore whether pointing stimuli are processed differently in the left and right visual fields. A repeated measures analysis of variance (ANOVA) with two levels of visual field (LVF, RVF) and three levels of pointing (CP, PP, FP) was performed separately on median RTs and error means. The main effect of visual field was significant for RT data, $F_{1}(1,31)=6.72, p=.0144 ; F_{2}(1,215)=$ 20.65, $p<.0001$, as well as for error data, $F_{1}(1$, $31)=18.05, p=.0002 ; F_{2}(1,215)=18.89$, $p<.0001$. Words presented in the RVF were named faster and with fewer errors $(442 \mathrm{~ms}$, $7.9 \%)$ than words presented in the LVF (460 ms, 12.7\%).

The main effect of pointing was significant for RT data, $F_{1}(2,62)=10.71, p<.0001 ; F_{2}(2$,

\footnotetext{
${ }^{3}$ The rather high error rates in Experiment 1 and Experiment 2 emerged due to a strict way of error count, including errors on both vowels and consonants. For example, the naming of the word אג אג (lake, /agam/) instead of the correct target word (pear, / agas/) was counted as error. Since this led to the exclusion of many participants from the data analyses, Appendices A and B provide the data analyses including all participants for Experiments 1 and 2, respectively.
} 
$430)=11.70, p<.0001$, as well as for error data, $F_{1}(2,62)=11.62, p<.0001 ; F_{2}(2,430)=9.53$, $p<.0001$, indicating that phonemic pointing (464 ms, 11.1\%) and figural pointing (455 ms, $12.2 \%)$ substantially prolonged response latencies and reduced accuracy relative to correctly pointed words (436 ms, 7.5\%).

The interaction between visual field and pointing was significant for response latency by participants, $F_{1}(2,62)=5.29, p=.0076$, but not by items, $F_{2}(2,418)=1.39, p=.2504 .{ }^{4}$ The interaction was not significant for accuracy data, $F_{1}(2$, $62)=1.25, p=.2949 ; F_{2}<1$.

In order to explore this interaction in response latency more closely, the patterns of pointing interference were compared for each visual field. Due to the different basic performance levels of the left and right visual fields - as indicated by the main effect of visual field - the amount of phonemic and figural interference cannot be compared directly. A relative interference measure was calculated separately for each visual field (and participant) by subtracting the median of correct pointing from each of the incorrect pointing medians: phonemic minus correct pointing for phonemic pointing interference (PI), and figural minus correct pointing for figural pointing interference (FI). The left panel of Figure 1 depicts these interference patterns.

The interaction between visual field and pointing interference was significant by participants, $F_{1}(1,31)=8.28, p=.0072 ; F_{2}<1$, and confirmed the above cited interaction of different performance patterns in the unilateral visual fields. Planned comparisons between the pointing interference for each visual field indicated that in the LVF, figural and phonemic pointing interfered with naming to the same degree $\left(F_{1}<1 ; F_{2}<1\right)$, whereas in the RVF phonemic pointing induced significantly more interference than did figural pointing, $F_{1}(1,31)=5.53, p=.0253 ; F_{2}(1$, 209) $=2.48, p=.1167 . .^{5}$

\section{Central visual field performance}

A repeated measures ANOVA with three levels of visual field (CVF, LVF, RVF) and three levels of pointing (CP, PP, FP) displayed a highly significant main effect of visual field both for RT data, $F_{1}(2,62)=92.14, p<.0001 ; F_{2}(2,430)=$ 192.14, $p<.0001$, and for error data, $F_{1}(2$, $62)=53.60, p<.0001 ; F_{2}(2,430)=77.21$, $p<.0001$. Post hoc analyses (Newman-Keuls) indicated that naming responses were significantly faster and more accurate when words were presented centrally ( $371 \mathrm{~ms}, 1.2 \%$ errors) than in either of the peripheral presentations (RVF: $442 \mathrm{~ms}, 7.9 \%$; LVF: $460 \mathrm{~ms}, 12.7 \%)$. Although phonemic pointing interference $(20 \mathrm{~ms})$ was larger than figural pointing interference $(14 \mathrm{~ms})$, this difference was not significant, $F_{1}(1,31)=$ $1.36, p=.2524 ; F_{2}<1$, though it was significant in the participants analysis when all participants were included, $F_{1}(1,39)=7.18, p=.0108$, see Appendix A.

The interference pattern in the CVF did not significantly differ from the interference patterns in either of the peripheral visual fields, as indicated by nonsignificant interactions between pointing interference (PI, FI) and visual field: CVF $\times$ LVF, $F_{1}(1,31)=1.02, p=.3204 ; F_{2}<1$, and $\mathrm{CVF} \times \mathrm{RVF}, F_{1}(1,31)=2.21, p=.1470 ; F_{2}<1$.

\section{Discussion of results}

Phonemically incorrect pointing produced strong interference in the CVF and thus replicated findings by previous studies under normal reading conditions, where stimuli were presented in central vision (Navon \& Shimron, 1981, 1985; Shimron \& Navon, 1982).

The main focus of Experiment 1, however, was to investigate whether the left and right hemispheres process phonological and visual-form information (as conveyed by pointing) differently. Results showed that in both unilateral visual fields

\footnotetext{
${ }^{4}$ The interaction between visual field and pointing was significant by items when all participants were included in the analyses, $F_{2}(2,424)=4.90, p<.0079$.

${ }^{5}$ The difference between figural and phonemic pointing interference in the RVF was significant by items when all participants were included in the analyses, $F_{2}(1,211)=6.72, p<.0102$.
} 

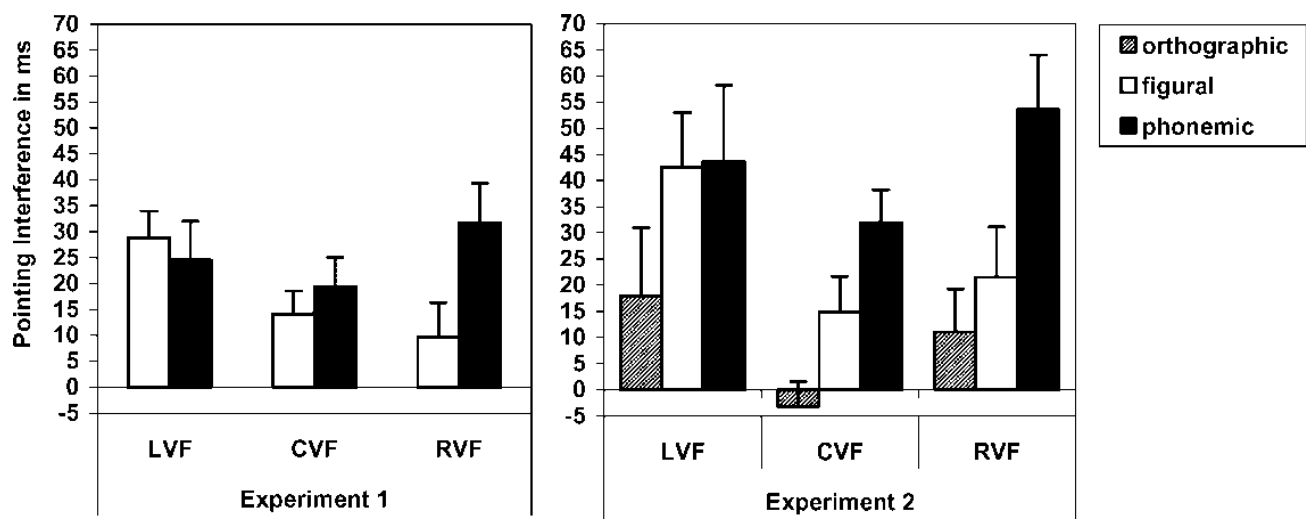

Figure 1. Pointing interference (incorrect minus correct pointing) with naming latencies for words presented in the left (LVF), central $(C V F)$, or right $(R V F)$ visual fields in Experiment 1 (left panel) and Experiment 2 (right panel).

phonemically incorrect pointing interfered with the correct naming of words. Because phonological and visual noise are confounded in the phonemic pointing condition, the comparison with figural pointing, which induces only visual noise, should indicate whether pointing is processed in a phonological or visual-form manner.

In the RVF, phonemic pointing interfered with word recognition to a considerably higher degree than did figural pointing, indicating that naming in the RVF was mostly impaired by phonological noise and less so by visual noise. In contrast, in the LVF, figural pointing interfered with naming to the same extent as did phonemic pointing, suggesting that the $\mathrm{RH}$ encodes pointing in a visual manner. This kind of $\mathrm{RH}$ performance may reflect the processing of a neural subsystem that identifies the specific exemplars of visual forms during the reading process. Indeed, this type of form-specific encoding system has been suggested to operate more efficiently in the RH than in the LH (Burgund \& Marsolek, 1997; Marsolek, 1999; Marsolek, Kosslyn, \& Squire, 1992).

\section{EXPERIMENT 2}

The aim of Experiment 2 was (a) to examine the dependence or independence of orthographic and phonological processing in the two cerebral hemispheres, and (b) to deconfound the phonological and visual noise presented in the phonemic pointing condition. For this purpose, we added an orthographic pointing condition in which the phonological form of the diacritic was correct, while the orthographic form was incorrect (see Table 1).

In central presentation conditions, this type of graphemic distortion did not interfere with naming to the same degree as did phonemic distortion, though it significantly delayed responses in a lexical decision task, indicating that the visually unusual pattern of the orthographic pointing condition was apparent to participants (Navon \& Shimron, 1981, 1985). Thus, orthographic distortion and phonemic distortion are visually different from correct pointing to a similar degree, but phonemic distortion is also phonologically dissimilar from correct pointing, whereas orthographic distortion is phonologically equivalent to correct pointing. The interference effects of these conditions allow the comparison of hemispheric sensitivity to the phonological and visual dimensions of pointing.

\section{Method}

\section{Participants}

A total of 42 Haifa university students who had not taken part in Experiment 1 participated in the experiment for course credit. They were 
right-handed native speakers of Hebrew, were not dyslexic, had not suffered from brain injuries, and had normal or corrected-to-normal vision.

\section{Stimuli}

The stimuli consisted of the same 216 Hebrew nouns as those used in Experiment 1. In addition to the three pointing conditions used in Experiment 1 -correct pointing $(\mathrm{CP})$, phonemic pointing (PP), and figural pointing (FP) —an orthographic pointing (OP) condition was included. In the orthographic pointing condition, correct diacritics were exchanged with diacritics that were orthographically incorrect but preserved the correct vowel pronunciation. Specifically, diacritics representing vowel /a/, "kamats" and "patah", were interchanged, as were diacritics representing vowel / $\varepsilon /$, "segol" and "tsere".

\section{Procedure}

Each of the 216 words appeared in all pointing (CP, PP, FP, OP) by visual field (CVF, LVF, $\mathrm{RVF}$ ) conditions. The different conditions of the same word were allocated to 12 lists by a Latin square design. Each list was further subdivided into three blocks of 72 items each. Stimulus items and presentation conditions within a list were randomized as in Experiment 1. Participants were randomly assigned to a list and practised with 48 trials prior to the experiment. Apparatus and experimental testing procedures, including stimulus presentation, testing conditions, and instructions to the participants were the same as those in Experiment 1.

\section{Results}

Data and outliers were treated according to the same principles as those in Experiment 1, so that 28 participants remained in the data analyses (mean error rate was 5.8\%). Median RTs and error means over participants were positively correlated, $r(334)=.38, p<.0001$, and are summarized in Table 3.

\section{Visual field differences}

A repeated measures ANOVA with two levels of visual field (LVF, RVF) and four levels of pointing $(\mathrm{CP}, \mathrm{PP}, \mathrm{FP}, \mathrm{OP})$ was run separately on median RTs and error means. On the whole, the findings of Experiment 1 were replicated. The main effect of visual field was significant for RT data, $F_{1}(1$, $27)=26.35, p<.0001 ; F_{2}(1,215)=10.39$, $p=.0015$, as well as for error data, $F_{1}(1,27)=$ $14.75, p=.0007 ; F_{2}(1,215)=15.68, p<$ .0001 . Words presented in the RVF $(470 \mathrm{~ms}$; $6.3 \%$ ) were responded to faster and with fewer errors than words presented in the LVF (498 ms, $10.3 \%)$.

Response latency showed a significant main effect of pointing, $F_{1}(3,81)=12.89, p<.0001$; $F_{2}(3,645)=8.81, p<.0001$, as did response

Table 3. Response latencies and accuracies in Experiment 2

\begin{tabular}{|c|c|c|c|c|c|c|c|c|c|}
\hline \multirow[b]{2}{*}{$\begin{array}{l}\text { Type of } \\
\text { pointing }\end{array}$} & \multicolumn{3}{|c|}{$L V F$} & \multicolumn{3}{|c|}{$C V F$} & \multicolumn{3}{|c|}{$R V F$} \\
\hline & $R T$ & Interference & Error & $R T$ & Interference & Error & $R T$ & Interference & Error \\
\hline Correct & $472(80)$ & & 8.1 & $384(62)$ & & 0.2 & $448(83)$ & & 4.8 \\
\hline Phonemic & $515(115)$ & $44^{* *}$ & 11.9 & $416(79)$ & $32 * *$ & 2.0 & $502(105)$ & $54^{* *}$ & 10.0 \\
\hline Figural & $514(92)$ & $43^{* *}$ & 10.7 & $398(79)$ & $15^{* *}$ & 0.4 & $470(95)$ & $22^{*}$ & 6.2 \\
\hline Orthographic & 490 (102) & (18) & 10.6 & $381(56)$ & $(-3)$ & 0.6 & $459(81)$ & (11) & 4.3 \\
\hline
\end{tabular}

Note: Median RTs in ms (SD in parentheses) and error means of naming responses for correctly, phonemically, figurally, and orthographically pointed words presented in the left (LVF), central (CVF), or right (RVF) visual fields. Interference effects are calculated relative to the correct pointing condition. Nonsignificant effects are given in parentheses.

${ }^{*} p<.05$ indicates significance level in the participants analysis; ${ }^{* *} p<.05$ indicates significance levels in both participants and items analyses.

\section{0}


accuracy, $F_{1}(3,81)=5.22, p=.0024 ; F_{2}(3,645)=$ $5.20, p=.0015$. Correctly pointed words $(460 \mathrm{~ms}$, $6.5 \%)$ were responded to faster and with fewer errors than words with orthographic $(475 \mathrm{~ms}$, $7.4 \%)$, figural (492 ms, 8.5\%), or phonemic (509 ms, 11.0\%) pointing.

The visual field by pointing interaction for response latency was not significant by participants, $F_{1}(3,81)=1.63, p=.1890$, though it was by items, $F_{2}(3,591)=2.69, p=.0453$. However, an ANOVA without the orthographic pointing condition-that is, with two levels of visual field and three levels of pointing - replicated the visual field by pointing interaction found in Experiment 1 both by participants and by items, $F_{1}(2,54)=3.03, p=.0568 ; F_{2}(2,386)=3.27$, $p=.0391$. As in Experiment 1, the interaction was not significant for error data, $F_{1}(3,81)=$ $1.09, p=.3600 ; F_{2}(3,625)=1.40, p=.2428$.

The relative interference effects caused by the different pointing conditions were calculated as in Experiment 1. Separately for each visual field and participant, the median of the correct pointing condition was subtracted from the median of figural, phonemic, or orthographic pointing to yield the medians for figural (FI), phonemic (PI), and orthographic (OI) pointing interference, respectively. These interference patterns are depicted in the right-panel of Figure 1.

Planned comparisons of the pointing interference in the LVF revealed that figural pointing produced the same amount as did phonemic pointing $\left(F_{1}<1 ; F_{2}<1\right)$, and significantly more interference than did orthographic pointing, $F_{1}(1,54)=$ $5.24, p=.0261 ; F_{2}(1,194)=9.74, p=.0021$. In contrast, in the RVF, figural pointing did not interfere significantly more with naming than did orthographic pointing $\left(F_{1}<1 ; F_{2}<1\right)$. However, phonemic pointing produced significantly more interference than did both figural pointing, $F_{1}(1,54)=8.86, p=.0044 ; F_{2}(1$, $203)=6.84, p=.0096$, and orthographic pointing, $F_{1}(1,54)=15.62, p=.0002 ; F_{2}(1,199)=$ 7.60, $p=.0064$. To summarize, in the LVF, both figural and phonemic pointing interfered with naming responses in comparison to orthographic pointing, whereas in the RVF, phonemic pointing produced the most interference in contrast to all other pointing conditions.

\section{Central visual field performance}

A repeated measures ANOVA with three levels of visual field (CVF, LVF, RVF) and four levels of pointing $(\mathrm{CP}, \mathrm{PP}, \mathrm{FP}, \mathrm{OP})$ was run separately on median RTs and error means and replicated the findings of Experiment 1. The main effect of visual field was significant for both RT data, $F_{1}(2,54)=123.72, p<.0001 ; F_{2}(2,430)=$ $168.51, p<.0001$, and error data, $F_{1}(2,54)=$ 49.94, $p<.0001 ; F_{2}(2,430)=53.33, p<$ .0001. Performance was faster and more accurate in the central visual field ( $395 \mathrm{~ms}, 0.8 \%$ errors) than in the peripheral visual fields (RVF: $470 \mathrm{~ms}, 6.3 \%$; LVF: $498 \mathrm{~ms}, 10.3 \%)$. Post hoc analyses (Newman-Keuls) confirmed that in both response measures the differences between all three visual field conditions were significant by participants and by items.

The effect of pointing interference in the CVF was significant, $F_{1}(2,54)=14.05, p<.0001$; $F_{2}(2,428)=9.41, p<.0001$, and is depicted in the right panel of Figure 1. Planned comparisons revealed that figural pointing produced significantly more interference than orthographic pointing, $F_{1}(1,54)=7.34, p=.0090 ; F_{2}(1,215)=$ $5.57, p=.0191$. Furthermore, phonemic pointing interfered with naming responses even more than did figural pointing, $F_{1}(1,54)=6.71, p=$ $.0123 ; F_{2}(1,213)=4.59, p=.0333$.

As in Experiment 1, the pointing interference pattern in the CVF did not differ significantly from either of the patterns in the peripheral visual fields, as indicated by nonsignificant interactions between pointing interference (PI, FI, OI) and visual field: CVF $\times$ LVF, $F_{1}<1 ; F_{2}(2$, $387)=1.43, p=.2395$, and $\mathrm{CVF} \times \mathrm{RVF}, F_{1}<$ $1 ; F_{2}<1$.

\section{Comparison of Experiments 1 and 2}

The comparison of the left and the right panels of Figure 1 illustrates that the results of Experiment 2 replicated those of Experiment 1. To confirm this, an ANOVA with between-subjects variable 
experiment (Experiment 1, Experiment 2) and repeated measures variables visual field (RVF, CVF, LVF) and pointing interference (FI, PI) was conducted. The main effect of experiment was marginally significant by participants, $F_{1}(1$, $58)=3.68, p=.0601$, but not by items, $F_{2}(1$, $383)=1.27, p=.2601$. Though only marginally significant, this effect indicates that the pointing interference was larger in Experiment 2 (35 ms) than in Experiment 1 (21 ms), as shown in Tables 2 and 3. Most importantly, the variable experiment did not influence any other variable. The two-way interaction between visual field and pointing interference was significant, $F_{1}(2,116)$ $=6.11, p=.0030 ; F_{2}(2,766)=3.62, p=$ .0274 , and replicated the interactions found in Experiments 1 and 2.

\section{Discussion of results}

Although the interference effects were generally larger in Experiment 2 than in Experiment 1, the results of Experiment 2 replicated the interference patterns of Experiment 1: In the RVF, word recognition was significantly more impaired by phonemic distortion than it was by figural distortion. Strong interference by phonological noise relative to weak interference by visual noise supports the hypothesis that the LH encodes diacritics primarily as phonological information.

In the LVF, in both experiments, phonemically incorrect pointing interfered with naming to the same extent as did figural pointing, suggesting that pointing is processed in a purely visual way. However, the complete lack of interference by orthographic pointing (included in Experiment 2), which induces visual noise just as phonemic and figural pointing do, showed that this simple interpretation does not hold. Rather, the LVF seems to be sensitive to the phonological identity of the orthographically distorted stimuli. This result ascribes importance to the contribution of the $\mathrm{RH}$ to normal reading and is discussed below.

The findings of Experiment 2 in the CVF replicated previous studies using central vision presentations (Navon \& Shimron, 1981, 1985) in that phonemically incorrect pointing strongly interfered with naming latencies, whereas orthographically incorrect pointing did not. Furthermore, the finding that phonemically incorrect pointing strongly interfered with word recognition replicated the findings in the $\mathrm{CVF}$ of Experiment 1. Moreover, in both experiments, phonemic pointing caused larger interference effects than did figural pointing $(20 \mathrm{~ms}$ vs. $14 \mathrm{~ms}$ in Experiment 1; $32 \mathrm{~ms}$ vs. $15 \mathrm{~ms}$ in Experiment 2). However, this difference was significant in Experiment 2, but not in Experiment 1 (though it was significant when the analysis of Experiment 1 included all participants, see Appendix A). We assume that this difference in statistical effects is due to the fact that phonemic distortion resulted in larger interference effects in Experiment 2 (32 $\mathrm{ms})$ than in Experiment 1 $(20 \mathrm{~ms})$, whereas figural distortion had the same effect in both experiments (14 $\mathrm{ms}$ and $15 \mathrm{~ms}$ in Experiments 1 and 2, respectively).

Similar to Experiment 1, the interference pattern in the central visual field did not differ from either of the peripheral visual field patterns. This suggests that the pattern in the central viewing condition is not controlled by only one hemisphere and supports the hypothesis that the $\mathrm{RH}$ contributes to normal reading.

\section{GENERAL DISCUSSION}

The present study investigated hemispheric processing differences in visual word recognition. First, a strong RVF/LH advantage was found in both experiments, with words being pronounced faster and more accurately when presented to the $\mathrm{RVF} / \mathrm{LH}$ than when projected to the LVF/RH. These findings converge with laterality studies conducted in both Latin-based and non-Latinbased writing systems. For example, studies conducted in English with nonimpaired participants (e.g., Ellis et al., 1988; Hellige, 1990) and with commissurotomy patients (e.g., Gazzaniga, 1995; Zaidel, 1990) provide converging evidence that the $\mathrm{LH}$ is dominant for language processing. Furthermore, studies established a RVF/LH 
superiority for Hebrew words, despite the rightto-left reading direction in Hebrew, which provides an acuity gradient that should favour the LVF/RH (e.g., Babkoff, Faust, \& Lavidor, 1997; Bentin, 1981; Eviatar, 1999; Faust, Kravetz, \& Babkoff, 1993). As such, the findings of the present study add to the generalization that the prevailing right visual field advantage for verbal stimuli is a true reflection of underlying hemispheric asymmetry and not an artifact of scanning habits.

The pointing by visual field interactions across experiments demonstrate a processing dissociation, which is interpreted as indicating differential hemispheric involvement in the processing of stimulus characteristics in the two visual fields (Hellige, 1993; Zaidel, 1983). In both experiments and in both visual fields, performance was affected by phonemic and figural pointing interference. Phonemic interference was equally strong in both visual fields, ${ }^{6}$ so that the phonemic interference effects as such are not informative about hemispheric processing. That is, they may reflect LH processing of all stimuli in both visual fields as well as independent but similar processes in the two hemispheres. However, in both experiments, figural distortion more strongly affected the LVF than the RVF. Moreover, figural pointing interference was equivalent to phonemic interference in the LVF, but significantly smaller than phonemic interference in the RVF.

This processing dissociation indicates that phonemic pointing interference originated from qualitatively different processes in the two visual fields and, by implication, in the two hemispheres. Phonemic interference could result from visual noise, phonological noise, or a combination of these two, whereas figural pointing represents visual noise without phonological meaning. Therefore, the differential interference effects in the two visual fields (see also the different visual field patterns in Figure 1) argue against the hypothesis that the $\mathrm{LH}$ processed all of the stimuli and rather suggest that the two hemispheres contribute differently to the processing of the phonological and visual/orthographic characteristics of the diacritics presented in the contralateral visual field (e.g., Coulson et al., 2005; Zaidel, 1983).

\section{Left-hemisphere processing}

In the RVF/LH, phonemic noise interfered more with word recognition than did visual noise, indicating that skilled Hebrew readers are able to ignore nonsense signs to a certain extent. However, if incorrect signs represent linguistic information, this input is processed in a phonological way, interfering with correct naming. The orthographic pointing condition, which preserved the correct sound of the word but misrepresented its orthographic configuration, provided a crucial control condition to test grapheme-to-phoneme conversion. The finding that only phonemic but not orthographic distortion resulted in interference supports the interpretation that the $\mathrm{LH}$ processes diacritics as phonological entities.

The distinction between phonemic and orthographic pointing does not represent the difference between sublexical and lexical processing per se, since both phonological and orthographic pointing are incorrect and cannot be read via the lexical path. Only if the incorrect diacritics are ignored do the consonants provide sufficient information to read aloud the word via the lexical path. The phonemic interference effects found in the present study suggest that graphemes are automatically encoded as phonological entities. Impaired performance in task situations, in which phonological computation is uncontrollable and unnecessary or even harmful to performance, provides a strong argument for automatic phonological processing (Besner \& Stolz, 1998;

\footnotetext{
${ }^{6}$ Phonemic interference was equally strong in both visual fields: Experiment $1,32 \mathrm{~ms}$ in RVF vs. $25 \mathrm{~ms}$ in LVF, $F_{1}<1 ; F_{2}(1$, $209)=3.06, p=.0820$; Experiment $2,54 \mathrm{~ms}$ in RVF vs. $44 \mathrm{~ms}$ in LVF, $F_{1}<1 ; F_{2}(1,182)=2.63, p=.1069$.

${ }^{7}$ Figural distortion more strongly affected the LVF than the RVF: Experiment $1,29 \mathrm{~ms}$ vs. $10 \mathrm{~ms}, F_{1}(1,31)=5.39, p=.0270$; $F_{2}<1$; Experiment $2,43 \mathrm{~ms}$ vs. $22 \mathrm{~ms}, F_{1}(1,27)=3.14, p=.0874 ; F_{2}<1$.
} 
Tzelgov, Henik, Sneg, \& Baruch, 1996). In the present study, the LH could have accessed the phonological form of the words without processing the provided diacritics, as it does when reading unpointed Hebrew. The fact that the $\mathrm{LH}$ was not able to ignore the vowel graphemes indicates that phonological processing is not under strategic control and that grapheme-tophoneme conversion was automatic.

A further question concerns the size of the phonological processing units that the LH encodes. For English, it has been suggested that LH coding "is oriented to larger units such as onsets or rimes, syllables, morphemes, or whole words" (Pugh et al., 1997, p. 312). In English, however, due to the intrinsic structure of the writing system, the study of phonological processing is confounded with the study of regularity effects and rhyming judgements. The manipulation of Hebrew orthography in the present study allowed us to examine the processing of single vowel graphemes as phonological units. From the phonemic interference effects we may thus conclude that the LH of Hebrew readers is oriented towards small phonological units and, more specifically, even towards single vowel graphemes.

The possibility that the LH is oriented towards the perception of single vowel representations has received support from auditory evoked magnetic field data: The distinction between vowels that differed in two features as compared to vowels that differed in only one feature was more pronounced in the LH than in the RH (Diesch, Eulitz, Hampson, \& Ross, 1996). These findings were interpreted as evidence that the phonetic perception of vowels is lateralized to the LH (Lund, Spliid, Andersen, \& Bojsen-Moller, 1986).

\section{Right-hemisphere processing}

In both experiments, phonemic pointing impaired performance not only in the RVF but also in the LVF. However, contrary to the
$\mathrm{RVF}$, in both experiments the LVF/RH was impaired by phonemic pointing just as it was by figural pointing. The fact that the interference by phonemic pointing resembled that by figural pointing suggested that the $\mathrm{RH}$ processes graphemes as visual signs that are not language specific. However, in Experiment 2, graphemic distortion did not result in significant interference in the LVF. This finding gives rise to different interpretations.

Assuming that the neurologically intact participants of the present study possess a functioning corpus callosum, the view of hemispheric interdependence suggests that the LH interactively contributes to the phonological processing of stimuli presented in the LVF. Under this assumption, the $\mathrm{RH}$ cannot assemble phonology from orthography, but can map familiar visual patterns onto some representation of meaning. The LH may have contributed to the recognition of the stimuli presented in the LVF, resulting in a lack of orthographic interference effect and a strong phonemic interference effect. Under this view, performance in the orthographic and phonemic distortion conditions in the LVF reflect both RH abilities and LH contribution. ${ }^{8}$

However, as discussed above, the figural interference in the LVF emphasized RH abilities and differed from that in the RVF. This processing dissociation indicates that the initial processing of all stimulus characteristics presented in the LVF enhances the contribution of the RH. On the view of hemispheric independence, the results suggest that the $\mathrm{RH}$ is able to store orthographic units according to phonological categories. This knowledge may stem from the same mechanism that allows the $\mathrm{RH}$ to know that different letter shapes such as "A" and "a" belong to the same category in letter-matching tasks. Indeed, the disconnected $\mathrm{RH}$ of commissurotomy patients was found capable of this type of categorical judgement (Eviatar \& Zaidel, 1994). Orthographic information being stored in phonological categories would also

\footnotetext{
${ }^{8}$ We thank David Plaut for suggesting this interpretation.
}

\section{4}


explain the findings that the $\mathrm{RH}$ of nonimpaired readers could detect rhyming words but was not able to perform the rhyme judgements (Rayman \& Zaidel, 1991). Furthermore, this RH mechanism may subserve a compensatory strategy when phonological assembly is required. Such a compensatory function of the $\mathrm{RH}$ has been supported by studies on developmental dyslexics whose LH lacked the functional connectivity (between occipital and temporal sites and the angular gyrus) found in nonimpaired readers (Pugh et al., 2000).

\section{Central presentation and normal reading}

In central vision, the results of both experiments showed that phonemically incorrect pointing strongly interferes with the correct naming of words and thus replicated the findings of previous studies applying central vision presentations. Both in Hebrew (Navon \& Shimron, 1981, 1985; Shimron \& Navon, 1982) and in Arabic (Bentin \& Ibrahim, 1996), interference effects were taken as indication that phonological information is automatically processed in visual word recognition.

Seidenberg (1992) has argued that word frequency is the primary factor that determines whether or not phonology is assembled to access the lexicon: In any orthography, whether deep or shallow, frequently seen words will become familiar visual-orthographic patterns, so that rapid visual access will occur before the presumably slower phonological code can be assembled from print. In the present study, relatively highfrequency words were used. The fact that performance in all visual fields was impaired by phonemic pointing implies that even familiar visualorthographic patterns are not solely accessed as whole forms.

The examination of Figure 1 suggests that the performance pattern in central presentations is more similar to the performance pattern in the $\mathrm{RVF} / \mathrm{LH}$ than to the pattern in the $\mathrm{LVF} / \mathrm{RH}$. However, the CVF patterns in the present study did not significantly differ from either of the patterns in the unilateral visual fields, suggesting that both hemispheres are involved in normal reading.
Although both hemispheres are sensitive to visual and phonological aspects of graphemes, there are clear differences in the relative weights given to these aspects in the two hemispheres. Our results support the hypothesis that each of the hemispheres contributes to normal reading via a different neural network (Peleg et al., 2005). In the LH network, the representations of orthographic, phonological, and semantic information are highly interconnected, whereas in the $\mathrm{RH}$ network, orthographic and phonological representations lack connectivity but are connected with semantic representations. Indeed, our results showed that the LH automatically computes graphemes as phonological information, whereas in the $\mathrm{RH}$, graphemes are primarily processed as visual forms. Nevertheless, the RH possesses some phonological information about these graphemes, most probably because it is able to categorize orthographic information according to phonological principles (via semantic/categorical representations).

$$
\begin{array}{r}
\text { Manuscript received 6 April } 2004 \\
\text { Revised manuscript received 6 June } 2005 \\
\text { Revised manuscript accepted 21 February } 2006 \\
\text { First published online 10 May } 2006
\end{array}
$$

\section{REFERENCES}

Babkoff, H., Faust, M., \& Lavidor, M. (1997). Lexical decision, visual hemifield and angle of orientation. Neuropsychologia, 35, 487-495.

Baynes, K., \& Eliassen, J. C. (1998). The visual lexicon: Its access and organization in commissurotomy patients. In M. Beeman \& C. Chiarello (Eds.), Right hemisphere language comprehension: Perspectives from cognitive neuroscience (pp. 79-104). Mahwah, NJ: Lawrence Erlbaum Associates, Inc.

Beeman, M. (1998). Coarse semantic coding and discourse comprehension. In M. Beeman \& C. Chiarello (Eds.), Right hemisphere language comprehension: Perspectives from cognitive neuroscience (pp. 255-284). Mahwah, NJ: Lawrence Erlbaum Associates, Inc.

Bentin, S. (1981). On the representation of a second language in the cerebral hemispheres of righthanded people. Neuropsychologia, 19, 599-603. 
Bentin, S., \& Frost, R. (1987). Processing lexical ambiguity and visual word recognition in a deep orthography. Memory and Cognition, 15, 13-23.

Bentin, S., \& Ibrahim, R. (1996). New evidence for phonological processing during visual word recognition: The case of Arabic. Journal of Experimental Psychology: Learning, Memory, and Cognition, 22, 309-323.

Berman, R. A. (1997). Modern Hebrew. In R. Hetzron (Ed.), The Semitic languages (pp. 312-333). New York: Routledge.

Besner, D., \& Stolz, J. A. (1998). Unintentional reading: Can phonological computation be controlled? Canadian Journal of Experimental Psychology, 52, 35-42.

Burgund, E. D., \& Marsolek, C. J. (1997). Letter-casespecific priming in the right cerebral hemisphere with a form-specific perceptual identification task. Brain and Cognition, 35, 239-258.

Castles, A., \& Coltheart, M. (1993). Varieties of developmental dyslexia. Cognition, 47, 149-180.

Castles, A., \& Coltheart, M. (1996). Cognitive correlates of developmental surface dyslexia: A single case study. Cognitive Neuropsychology, 13, 25-50.

Chiarello, C. (1985). Hemisphere dynamics in lexical access: Automatic and controlled priming. Brain and Language, 26, 146-172.

Chiarello, C. (1988). Lateralization of lexical processes in the normal brain: A review of visual half-field research. In H. A. Whitaker (Ed.), Contemporary reviews in neuropsychology (pp. 36-76). New York: Springer.

Chiarello, C. (1998). Semantic priming in the intact brain: Separate roles for the right and left hemispheres? In C. Chiarello (Ed.), Right hemisphere contributions to lexical semantics (pp. 59-69). Heidelberg, Germany: Springer.

Coltheart, M. (2000). Deep dyslexia is right-hemisphere reading. Brain and Language, 299-309.

Coltheart, M., Curtis, B., Atkins, P., \& Haller, M. (1993). Models of reading aloud: Dual-route and parallel-distributed-processing approaches. Psychological Review, 100, 589-608.

Coltheart, M., Rastle, K., Perry, C., Langdon, R., \& Ziegler, J. (2001). DRC: A dual route cascaded model of visual word recognition and reading aloud. Psychological Review, 108, 204-256.

Coney, J. (2002). Lateral asymmetry in phonological processing: Relating behavioral measures to neuroimaged structures. Brain and Language, 80, 355-365.
Copland, D. A., Chenery, H. J., \& Murdoch, B. E. (2002). Hemispheric contributions to lexical ambiguity resolution: Evidence from individuals with complex language impairment following left hemisphere lesions. Brain and Language, 81, 131-143.

Coslett, H. B., \& Saffran, E. M. (1998). Reading and the right hemisphere: Evidence from acquired dyslexia. In M. Beeman \& C. Chiarello (Eds.), Right hemisphere language comprehension: Perspectives from cognitive neuroscience (pp. 105-132). Mahwah, NJ: Lawrence Erlbaum Associates, Inc.

Coulson, S., Federmeier, K. D., Van Petten, C., \& Kutas, M. (2005). Right hemisphere sensitivity to word and sentence level context: Evidence from eventrelated brain potentials. Manuscript submitted for publication.

Diesch, E., Eulitz, C., Hampson, S., \& Ross, B. (1996). The neurotopography of vowels as mirrored by evoked magnetic field measurements. Brain and Language, 53, 143-168.

Ellis, A. W., Young, A. W., \& Anderson, C. (1988). Modes of word recognition in the left and right cerebral hemispheres. Brain and Language, 35, 254-273.

Eviatar, Z. (1999). Cross-language tests of hemispheric strategies in reading nonwords. Neuropsychology, 13, 498-515.

Eviatar, Z. (2000). Culture and brain organization. Brain and Cognition, 42, 50-52.

Eviatar, Z., \& Zaidel, E. (1991). The effects of word length and emotionality on hemispheric contribution to lexical decision. Neuropsychologia, 29, 415-428.

Eviatar, Z., \& Zaidel, E. (1992). Letter matching in the hemispheres: Speed-accuracy tradeoffs. Neuropsychologia, 30, 699-710.

Eviatar, Z., \& Zaidel, E. (1994). Letter matching within and between the disconnected hemispheres. Brain and Cognition, 25, 128-137.

Faust, M., Kravetz, S., \& Babkoff, H. (1993). Hemispheric specialization or reading habits: Evidence from lexical decision research with Hebrew words and sentences. Brain and Language, 44, 254-263.

Frost, R. (1994). Prelexical and postlexical strategies in reading: Evidence from a deep and a shallow orthography. Journal of Experimental Psychology: Learning, Memory, and Cognition, 20, 116-129.

Frost, R. (1995). Phonological computation and missing vowels: Mapping lexical involvement in reading.

\section{6}


Journal of Experimental Psychology: Learning, Memory, and Cognition, 21, 398-408.

Frost, R. (1998). Toward a strong phonological theory of visual word recognition: True issues and false trials. Psychological Bulletin, 123, 71-99.

Frost, R., \& Bentin, S. (1992). Reading consonants and guessing vowels: Visual word recognition in Hebrew orthography. In R. Frost \& L. Katz (Eds.), Orthography, phonology, morphology, and meaning (pp. 27-44). Amsterdam: Elsevier.

Gazzaniga, M. S. (1995). Principles of human brain organization derived from split-brain studies. Neuron, 14, 217-228.

Goswami, U. (2002). In the beginning was the rhyme? A reflection on Hulme, Hatcher, Nation, Brown, Adams, and Stuart (2002). Journal of Experimental Child Psychology, 82, 47-57.

Goswami, U., Ziegler, J. C., Dalton, L., \& Schneider, W. (2003). Nonword reading across orthographies: How flexible is the choice of reading units? Applied Psycholinguistics, 24, 235-247.

Hanley, J. R., \& McDonnell, V. (1997). Are reading and spelling phonologically mediated? Evidence from a patient with a speech production impairment. Cognitive Neuropsychology, 14, 3-33.

Harm, M. W., \& Seidenberg, M. S. (2001). Are there orthographic impairments in phonological dyslexia? Cognitive Neuropsychology, 18, 71-92.

Hellige, J. B. (1990). Hemispheric asymmetry. Annual Review of Psychology, 41, 55-80.

Hellige, J. B. (1993). Hemispheric asymmetry. Cambridge, MA: Harvard University Press.

Iacoboni, M., \& Zaidel, E. (1996). Hemispheric independence in word recognition: Evidence from unilateral and bilateral presentations. Brain and Language, 53, 121-140.

Jackson, N. E., \& Coltheart, M. (2001). Routes to reading success and failure: Toward an integrated cognitive psychology of atypical reading. New York: Psychology Press.

Jordan, T. R., Patching, G. R., \& Thomas, S. M. (2003). Assessing the role of hemispheric specialisation, serial-position processing, and retinal eccentricity in lateralised word recognition. Cognitive Neuropsychology, 20, 49-71.

Katz, L., \& Frost, R. (1992). The reading process is different for different orthographies: The orthographic depth hypothesis. In R. Frost \& L. Katz (Eds.), Orthography, phonology, morphology and meaning (pp. 67-84). Amsterdam: Elsevier.
Koriat, A. (1984). Reading without vowels: Lexical access in Hebrew. In H. Bouma \& D. G. Bouwhuis (Eds.), Attention and performance $X$ : Control of language processes (pp. 227-242). Hove, UK: Lawrence Erlbaum Associates Ltd.

Koriat, A. (1985a). Lateralization effects in reading pointed and unpointed Hebrew. British Journal of Psychology, 76, 161-173.

Koriat, A. (1985b). Lexical access for low- and highfrequency words in Hebrew. Memory and Cognition, 13, 37-44.

Lavidor, M., \& Ellis, A. W. (2003). Orthographic and phonological priming in the two cerebral hemispheres. Laterality, 8, 201-223.

Lukatela, G., Lukatela, K., Carello, C., \& Turvey, M. T. (1999). Effects of frequency and phonological ambiguity on naming Serbo-Croatian words. European Journal of Cognitive Psychology, 11, 1-16.

Lund, E., Spliid, P. E., Andersen, E., \& BojsenMoller, M. (1986). Vowel perception: A neuroradiological study of the perception of vowels in the human cortex. Brain and Language, 25, 191-211.

Marsolek, C. J. (1999). Dissociable neural subsystems underlie abstract and specific object recognition. Psychological Science, 10, 111-118.

Marsolek, C. J., Kosslyn, S. M., \& Squire, L. R. (1992). Form-specific visual priming in the right cerebral hemisphere. Journal of Experimental Psychology: Learning, Memory, and Cognition, 18, 492-508.

Navon, D., \& Shimron, J. (1981). Does word naming involve grapheme-to-phoneme translation? Evidence from Hebrew. Journal of Verbal Learning and Verbal Behavior, 20, 97-109.

Navon, D., \& Shimron, J. (1985). Source and function of phonological codes in processing written Hebrew (Final report to the US-Israeli Binational Science Foundation). Haifa, Israel: University of Haifa, Institute of Information Processing and Decision Making.

Paap, K. R., Noel, R. W., \& Johansen, L. S. (1992). Dual-route models of print to sound: Red herrings and real horses. In R. Frost \& L. Katz (Eds.), Orthography, phonology, morphology, and meaning (pp. 293-318). Amsterdam: Elsevier.

Peleg, O., Eviatar, Z., Manevitz, L., \&Hazan, H. (2005). The disambiguation of heterophonic and homophonic homographs in Hebrew: A parallel distributed processing account. Paper presented at the 21st Annual Meeting of the Israel Association for Theoretical Linguistics (ISCOL), Technion, Haifa, Israel. 
Plaut, D. C. (1997). Structure and function in the lexical system: Insights from distributed models of word reading and lexical decision. Language and Cognitive Processes, 12, 765-805.

Pugh, K. R., Mencl, W. E., Shaywitz, B. A., Shaywitz, S. E., Fulbright, R. K., Constable, R. T., et al. (2000). The angular gyrus in developmental dyslexia: Taskspecific differences in functional connectivity within posterior cortex. Psychological Science, 11, 51-56.

Pugh, K. R., Shaywitz, B. A., Shaywitz, S. E., Shankweiler, D. P., Katz, L., Fletcher, J. M., et al. (1997). Predicting reading performance from neuroimaging profiles: The cerebral basis of phonological effects in printed word identification. Journal of Experimental Psychology: Human Perception and Performance, 23, 299-318.

Rayman, J., \& Zaidel, E. (1991). Rhyming and the right hemisphere. Brain and Language, 40, 89-105.

Rey, A., Ziegler, J. C., \& Jacobs, A. M. (2000). Graphemes are perceptual reading units. Cognition, 75, B1-B12.

Saffran, E. M., \& Marin, O. S. M. (1977). Reading without phonology: Evidence from aphasia. Quarterly Journal of Experimental Psychology, 29, 515-525.

Schweiger, A., Zaidel, E., Field, T., \& Dobkin, B. (1989). Right hemisphere contribution to lexical access in an aphasic with deep dyslexia. Brain and Language, 37, 73-89.

Scott, G. B., \& Hellige, J. B. (1998). Hemispheric asymmetry for word naming: Effects of frequency and regularity of pronunciation. Laterality, 3, 343-371.

Seidenberg, M. S. (1992). Beyond orthographic depth in reading: Equitable division of labor. In R. Frost \& L. Katz (Eds.), Orthography, phonology, morphology, and meaning (pp. 85-118). Amsterdam: Elsevier.

Seidenberg, M. S., \& McClelland, J. L. (1989). A distributed, developmental model of word recognition and naming. Psychological Review, 96, 523-568.

Shimron, J. (1993). The role of vowels in reading: A review of studies of English and Hebrew. Psychological Bulletin, 114, 52-67.

Shimron, J., \& Navon, D. (1982). The dependence on graphemes and on their translation to phonemes in reading: A developmental perspective. Reading Research Quarterly, 17, 210-228.

Taouk, M., \& Coltheart, M. (2004). The cognitive processes involved in learning to read in Arabic. Reading and Writing: An Interdisciplinary Journal, 17, 27-57.
Tompkins, C. A., \& Lehman, M. T. (1998). Interpreting intended meanings after right hemisphere brain damage: An analysis of evidence, potential account, and clinical implications. Topics in Stroke Rehabilitation, 5, 29-47.

Tzelgov, J., Henik, A., Sneg, R., \& Baruch, O. (1996). Unintentional word reading via the phonological route: The Stroop effect with crossscript homophones. Journal of Experimental Psychology: Learning, Memory, and Cognition, 22, 336-349.

Van Orden, G. C., Jansen op de Haar, M. A., \& Bosman, A. M. T. (1997). Complex dynamic systems also predict dissociations, but they do not reduce to autonomous components. Cognitive Neuropsychology, 14, 131-165.

Van Orden, G. C., Pennington, B. F., \& Stone, G. O. (1990). Word identification in reading and the promise of subsymbolic psycholinguistics. Psychological Review, 97, 488-522.

Wiese, R. (1996). The phonology of German. New York: Oxford University Press.

Zaidel, E. (1983). Disconnection syndrome as a model for laterality effects in the normal brain. In J. Hellige (Ed.), Cerebral hemisphere asymmetry: Method, theory, and application (pp. 95-151). New York: Praeger.

Zaidel, E. (1987). Language in the disconnected right hemisphere. Encyclopedia of neuroscience (pp. 563564). Cambridge, MA: Birkhauser.

Zaidel, E. (1990). Language functions in the two hemispheres following complete cerebral commissurotomy and hemispherectomy. In F. Boller \& G. Grafman (Eds.), Handbook of neuropsychology (Vol. 4, pp. 115-150). Amsterdam: Elsevier.

Zaidel, E. (1998). Language in the right hemisphere following callosal disconnection. In B. Stemmer \& H. Whitaker (Eds.), Handbook of neurolinguistics (pp. 369-383). New York: Academic Press.

Zaidel, E., \& Peters, A. M. (1981). Phonological encoding and ideographic reading by the disconnected right hemisphere: Two case studies. Brain and Language, 14, 205-234.

Zaidel, E., Zaidel, D. W., \& Bogen, J. E. (1990): Testing the commissurotomy patient. In A. A. Boulton, G. B. Baker, \& M. Hiscock (Eds.), Neuropsychology: Vol. 17. Neuromethods (pp. 147201). Clifton, NJ: Humana Press.

\section{8}




\section{APPENDIX A}

The effects of pointing interference ${ }^{a}$ on naming responses in Experiment 1 including all participants.

\begin{tabular}{lccc}
\hline Pointing interference & LVF & CVF & RVF \\
\hline Phonemic & 20 & 23 & 34 \\
& $n s$ & $*$ & $* *$ \\
Figural & 25 & 9 & 14 \\
\hline
\end{tabular}

Note: $\mathrm{LVF}, \mathrm{CVF}$, and $\mathrm{RVF}=$ left, central, or right visual hemifields, respectively. The interaction between visual field (LVF, RVF) and pointing interference was significant, $F_{1}(1,39)=6.56, p=.0144 ; F_{2}(1,210)=7.37$, $p=.0072$.

${ }^{\mathrm{a}} \mathrm{In} \mathrm{ms}$.

${ }^{*} p<.05$ indicates significance level between conditions in the participants analysis; ${ }^{* *} p<.05$ indicates significance levels in both participants and items analyses; $n s=$ not significant.

\section{APPENDIX B}

The effects of pointing interference ${ }^{\mathrm{a}}$ on naming responses in Experiment 2 including all participants.

\begin{tabular}{lccc}
\hline Pointing interference & LVF & CVF & RVF \\
\hline Phonemic & 35 & 29 & 47 \\
& $n s$ & $* *$ & $* *$ \\
Figural & 25 & 16 & 24 \\
& $* *$ & $*$ & $n s$ \\
Orthographic & 8 & 0 & 16 \\
\hline
\end{tabular}

Note: $\mathrm{LVF}, \mathrm{CVF}$, and $\mathrm{RVF}=$ left, central, or right visual hemifields, respectively. The interaction between visual field (LVF, RVF) and pointing interference was not significant; however, the interference patterns replicated those of Experiment 1 and correspond to those of Experiment 2.

${ }^{\mathrm{a}}$ In ms.

${ }^{*} p<.05$ indicates significance level between conditions in the participants analysis; ${ }^{* *} p<.05$ indicates significance levels in both participants and items analyses; $n s=$ not significant. 